\title{
ПРОБЛЕМЫ РЕГЛАМЕНТАЦИИ ГОСУДАРСТВЕННЫХ УСЛУГ НА ПРИМЕРЕ СИБИРСКОГО ФЕДЕРАЛЬНОГО ОКРУГА
}

Аннотация. Предметом исследования данной работы является содержащийся в нормативно-правовых актах органов исполнительной власти Красноярского края, Кемеровской области и Республики Хакасия комплекс норм, касающийся предоставления государственных услуг. Автором был изучен массив административных регламентов по оказанию государственных услуг, а также официальные ресурсы органов государственной власти, где размещаются данные регламенты. В работе также рассматривается понятие «государственная услуга", приводятся основанные на федеральном законодательстве и теоретическом материале критерии её отграничения от государственной функции. В статье были использованы сравнительно-правовой и формально-юридический методы исследования, а также анализ и синтез. Кроме того, был использован статистический метод. Основные выводы проведённого исследования заключаются в том, что, исходя из анализа административных регламентов по оказанию государственных услуг и полученного статистического материала, сформулированы основные проблемы, и выявлены типовые ошибки, связанные с регламентацией государственных услуг. Также предложены меры по недопущению таких ошибок в будущем.

Ключевые слова: Административная реформа, административный регламент, государственное управление, государственная услуга, государственная функция, орган исполнительной власти, Сибирский федеральный округ, межведомственное взаимодействие, многофункциональный центр, субъект федерации Abstract. The research subject is the set of provisions on government services, contained in the statutory instruments of executive bodies of Krasnoyarski krai, Kemerovo region and the Republic of Khakassia. The author studies administrative regulations on government services and the official resources of public authorities, where these regulations can be found. The author considers the "government service" concept and describes the criteria of its distinguishing from the public function, based on the federal legislation and theoretical materials. The author applies the comparative-legal and formal-legal research methods, analysis, synthesis and the statistical method. On the base of the analysis of administrative regulations of government services and the acquired statistical data, the author formulates the basic problems and detects the typical drawbacks of government services regulation. The author offers the ways to avoid such drawbacks in the future.

Key words: constituent territory of the federation, multiservice center, interdepartmental interaction, Siberian Federal District, executive body, public function, government service, public administration, administrative regulation, administrative reform.

$\mathrm{B}$ настоящее время в субъектах Российской Федерации ведётся работа по принятию нормативно-правовых актов по регламентации порядка предоставления государственных услуг. Нередко в них содержатся ошибки, противоречащие действующему законодательству и, как следствие, затрудняющие соответствующую деятельность и вызывающие недовольство граждан. В этой связи представляется необходимым определить типовой набор таких ошибок, чтобы в дальнейшем не допускать их, и провести работу по устранению уже допущенных.

Прежде чем перейти к рассмотрению указанного вопроса необходимо определиться с тем, что представляет собой государственная услуга. В научной литературе понятие «государственная услуга» появилось давно. Однако этот термин в законодательстве прямо не употреблялся, хотя по содержанию предоставляемые гражданам услуги были не чем иным, как услугами государственны- ми [1]. Понятие «государственные услуги» в России на официальном уровне стало использоваться примерно с 2005 г. с началом административной реформы. Однако до сих пор нет чёткого критерия её отграничения от государственной функции, что нередко приводит органы государственной власти субъектов РФ в затруднительное положение.

В научной литературе некоторые авторы определяют государственную услугу как деятельность органов исполнительной власти, государственных внебюджетных фондов, осуществляемую по запросам заявителей и направленную на получение выгод в пределах, установленных нормативными правовыми актами государства [2]. Представляется, что такое определение не позволяет выявить сути государственной услуги, так как данный автор не уточняет, что такое выгода. Так, например, выгодой для заявителя (в плане укрепления конкурентных преимуществ) будет обращение с жалобой на недобросовестного конкурента в Федеральный анти- 
монопольный орган. Однако вряд ли можно назвать принятие жалобы услугой в этом случае.

В свою очередь, Л.В. Романюк отмечает, что «правильнее будет рассматривать государственную услугу в двух аспектах: как деятельность и как результат этой деятельности. То есть сущность и понимание государственной услуги как таковой заключается не только в государственно-властной деятельности публичной администрации, направленной на обеспечение условий для реализации прав физического либо юридического лица, которое осуществляется по его заявлению, но и непосредственно в достижении результата этой деятельности, направленной на юридическое оформление прав заявителя» [3]. Представляется, что следует согласиться с автором, так как государственные услуги, прежде всего, необходимы гражданам для реализации их конституционных прав, а не получения выгод.

Следует иметь в виду, что Указ Президента РФ от 9.03.2004 № 314 «О системе и структуре федеральных органов исполнительной власти» говорит о таком понятии как «функции по оказанию государственных услуг», под которыми понимается предоставление федеральными органами исполнительной власти непосредственно, или через подведомственные им федеральные государственные учреждения, либо иные организации безвозмездно, или по регулируемым органами государственной власти ценам услуг гражданам и организациям в области образования, здравоохранения, социальной защиты населения и в других областях, установленных федеральными законами [4]. Очевидно, что в данном случае государственная услуга понимается как один из видов государственных функций. Между тем, по мнению А.Г. Кравченко, «сама по себе концепция разделения функций органов государственной власти на «услуги» и «функции» предполагает, прежде всего, размежевание подходов к государственному управлению и выделение видов государственной деятельности, основанных на рыночных механизмах и принципах, а также государственной деятельности, которая в силу своей природы и назначения может быть реализована исключительно командно-административными механизмами самого государства» [5].

Таким образом, можно сказать, что государственная услуга - это одно из проявлений государственной функции. Понятие «государственная функция» является общим, а «государственная услуга» - специальным. Государственная функция это деятельность органов исполнительной власти по реализации властных полномочий, которые не связаны с непосредственным обращением гражданина (физического лица) или организации (юридического лица) в соответствующий орган исполни- тельной власти. В свою очередь, государственная услуга, в отличие от государственной функции, носит индивидуальный, адресный характер.

Перечень государственных услуг является открытым, не включает в себя какие-либо ограничения. При этом, из существа определения «государственная услуга» Федерального закона «Об организации предоставления государственных и муниципальных услуг» от 27.07.2010 № 210-Ф3 (далее - закон № 210-Ф3) [6] выявляется, что такое ограничение существует, а именно, что осуществление указанной деятельности возможно только в пределах компетенции соответствующего органа власти, а значит, если осуществление определённых видов деятельности не предполагает предметную компетенцию того или иного органа власти, тогда её нельзя будет считать государственной услугой.

Закон № 210-Ф3 устанавливает исчерпывающий перечень органов, которые предоставляют государственные услуги. К ним относятся федеральные органы исполнительной власти, органы государственного внебюджетного фонда, исполнительные органы власти субъектов РФ, органы местного самоуправления. Иные субъекты не имеют право оказывать государственные услуги.

Итак, «государственная услуга» означает деятельность уполномоченного органа, выражающуюся в совершении действий и (или) принятии решений, влекущих возникновение, изменение или прекращение правоотношений или создание документированной информации (документа) в связи с обращением гражданина или организации в целях реализации их прав, законных интересов либо исполнения возложенных на них нормативными правовыми актами обязанностей.

Порядок оказания государственных услуг, как отмечалось выше, закреплён в административных регламентах. Для того чтобы выявить типичные ошибки, содержащиеся в административных регламентах по оказанию государственных услуг, автором был проведён их анализ на примере некоторых субъектов Российской Федерации, входящих в Сибирский федеральный округ. Основу выборки составили государственные услуги, включённые в перечни государственных услуг, оказываемые органами субъектов Российской Федерации. В частности было изучено 68 административных регламентов Кемеровской области, 107 Красноярского края, 64 Республики Хакасия. В итоге был сделан ряд выводов.

Во-первых, в результате изучения был сделан вывод, что одной из типовых ошибок является отсутствие регламентации порядка предоставления государственных услуг в многофункциональных центрах предоставления государственных и му- 


\section{Административное и муниципальное право 10 (106) • 2016}

ниципальных услуг (далее - МФЦ). Эта ошибка обнаружена в 8,8 \% административных регламентов Кемеровской области, $12 \%$ административных регламентов Красноярского края и 9,3 \% административных регламентов Республики Хакасия. К таким актам относится Приказ министерства по делам Севера и поддержке коренных малочисленных народов Красноярского края от 30.06.2014 № 31-о «Об утверждении Административного регламента предоставления министерством по делам Севера и поддержке коренных малочисленных народов Красноярского края государственной услуги по предоставлению материальной помощи лицам из числа коренных малочисленных народов Российской Федерации, проживающим в Туруханском, Енисейском, Северо-Енисейском и Тюхтетском районах Красноярского края, в целях уплаты налога на доходы физических лиц за предоставленные товарно-материальные ценности» [7], который не содержит даже соответствующего раздела.

Во-вторых, рядом административных регламентов не предусмотрена процедура межведомственного взаимодействия, например, в регламенте, утверждённом распоряжением комитета по управлению государственным имуществом Кемеровской области от 05.04.2012 № 9-2/1180-р «Об утверждении административного регламента комитета по управлению государственным имуществом Кемеровской области по предоставлению государственной услуги «Предоставление государственного имущества Кемеровской области в аренду и безвозмездное пользование» [8]. В общей доле исследованных регламентов они составляют 5,9 \% в Кемеровской области, 15 \% в Красноярском крае и 21,8 \% в Республике Хакасия.

В-третьих, ряд административных регламентов устанавливает чрезмерно длительные сроки рассмотрения жалоб - 30 дней. К ним, в частности, относится Приказ Минкультуры Республики Хакасия от 25.05.2012 № 84 «Об утверждении Административного регламента Министерства культуры Республики Хакасия по предоставлению государственной услуги «Согласование проведения землеустроительных, земляных, строительных, мелиоративных, хозяйственных и иных работ и проектов проведения указанных работ» [9]. Кроме того, в регламенте, утверждённом приказом Департамента охраны здоровья населения Кемеровской области от 24.05.2010 № 638 «Об утверждении административного регламента предоставления государственной услуги «Направление граждан, нуждающихся в оказании дорогостоящих (высокотехнологичных) видов медицинской помощи, на консультации и лечение в федеральные клиники» [10], не указан срок направления ответа по рассмотренной жалобе. В общей доле исследованных регламентов данные ошибки занимают 7,4 \% в Кемеровской области, 9,3 \% в Красноярском крае, 1,5 \% в Республике Хакасия.

В-четвёртых, выявлено несоответствие указанного в административном регламенте размера госпошлины с теми, что установлены в Налоговом кодексе РФ. В Кемеровской области его содержат 1,4 \%, в Красноярском крае 2,8 \%, в Республике Хакасия $14 \%$ исследованных административных регламентов. Вызвано это тем, что региональное нормотворчество не успевает за частыми изменениями налогового законодательства. Решить данную проблему представляется возможным посредством внесения изменений в Постановление Правительства РФ от 16.05.2011 № 373 «О разработке и утверждении административных регламентов исполнения государственных функций и административных регламентов предоставления государственных услуг» [11], которые заключались бы в том, что в административные регламенты следует включать нормы, отсылающие к иным нормативным актам, содержащим динамически изменяющуюся информацию, например, к Налоговому кодексу РФ. Такой подход позволит осуществить превентивные меры по деактуализации административных регламентов, что не даст ввести получателя государственной услуги в заблуждение.

В-пятых, характерным нарушением является завышение времени ожидания в очереди - вместо 15 минут до 30 минут или 1 часа. В Кемеровской области его содержат 10 административных регламентов $(14,7 \%)$, в Красноярском крае - 9 (8,4 \%), в Республике Хакасия - 4 (6,25 \%). При этом в ряде случаев в административных регламентах закрепляется меньшее время для предоставления государственной услуги, чем 15 минут. Так, Приказом Министерства регионального развития Республики Хакасия от 19.02.2013 № 090-55-п [12] утверждена государственная услуга по выдаче заключения о соответствии построенного, реконструированного объекта капитального строительства требованиям технических регламентов и проектной документации. Время ожидания в очереди для подачи заявления о предоставлении данной услуги составляет 10 минут. С одной стороны такой подход более ориентирован на заявителей, однако, с другой стороны, вряд ли стоит повышать нагрузку на госслужащих.

B-шестых, анализ опубликованных на официальном сайте субъектов РФ нормативных актов показывает, что органами власти субъектов РФ публикуются устаревшие редакции административных регламентов, либо публикуются лишь приказы об их утверждении без текста самого регламента, также затруднено нахождение нормативных документов потенциальными потребителями услуг, 
что нарушает требование ст. 5 закона № 210-Ф3 и препятствует информированности потребителей электронных услуг о порядке их предоставления. Данная практика была достаточно распространена в Кемеровской области и в Республике Хакасия. Однако, в 2016 году были созданы информационные ресурсы, которые значительно упростили поиск нормативных документов. Кроме того, были выявлены административные регламенты, которые являются фактически отменёнными в связи с принятием новых административных регламентов по тому же предмету регулирования, но которые на официальном сайте субъекта РФ не обозначены как утратившие силу.

В-седьмых, существует проблема, связанная с изменением полномочий органов власти, осуществляющих предоставление государственных услуг. Уполномоченный на предоставление услуги орган власти формально в соответствии с действующим регламентом данную услугу не осуществляет. Тем самым возникает путаница у граждан-заявителей и формально-юридически аннулирует сам административный регламент, создавая правовой пробел.

Представляется, что наличие названных выше проблем во многом связано не только с ошибками регионального нормотворчества, но и с частым изменением федерального законодательства. В связи с этим законодателю следует разработать меры контроля и ответственности за несвоевременную актуализацию административных регламентов. Кроме того, видится необходимым создание рамочных (типовых) административных регламентов по типовым государственным услугам. Централизованная разработка шаблона регламента предоставления государственных услуг и его своевременная актуализация на федеральном уровне значительно упрощают законодательную работу в субъектах РФ. При этом следует учитывать, что необходимость создания типовых администра- тивных регламентов обусловлена ещё и тем, что в настоящее время, исполняя требования Постановления Правительства Российской Федерации 16.05.2011 № 373 «О разработке и утверждении административных регламентов исполнения государственных функций и административных регламентов предоставления государственных услуг», органы исполнительной власти субъекта РФ занимаются тем, что практически дословно копируют для заполнения административных регламентов положения федерального законодательства. Очевидно, что такое копирование занимает законодательный ресурс, создаёт необходимость контрольно-надзорных органов в каждом конкретном случае проверять универсальные по своей природе блоки юридических текстов административных регламентов, поскольку в любой из них может быть добавлена региональная или муниципальная формулировка, противоречащая закону. Как было указано выше, такие искажения касаются, как правило, сроков предоставления государственных услуг, ожидания в очереди, обжалования принятых решений.

Таким образом, характеризуя текущее состояние правовой регламентации порядка оказания государственных услуг в некоторых субъектах Сибирского федерального округа, следует отметить, что присутствует противоречие федеральному законодательству положений ряда административных регламентов; имеется слабая активность органов власти по соблюдению законодательства об информационной открытости порядка предоставления государственных (муниципальных) услуг. В связи с вышеизложенным необходимо провести актуализацию административных регламентов в структурном плане. Прежде всего, следует предусмотреть наличие типовых разделов административных регламентов с универсальным содержанием.

\section{Библиография:}

1. Васильев В.И. Гражданин, закон и публичная власть: монография / И.В. Васильев, А.А. Гравина, Е.А. Курочкина. М.: Норма, 2005. 368 с.

2. Руденко И.А. Понятие и сущность государственной услуги / И.А. Руденко // Вестник Саратовского государственного социально-экономического университета. 2014. № 3. С. 68-71.

3. Романюк Л.В. Государственная услуга как одна из основных категорий государственного управления: понятие, сущность, содержание / Л.В. Романюк // Учёные записки Таврического национального университета им. В.И. Вернадского. 2014. Т. 27(66). № 3. - Серия «Юридические науки». С. 119-122.

4. О системе и структуре федеральных органов исполнительной власти: Указ Президента РФ от 9.03 .2004 № 314 [Электронный ресурс] // СПС «Консультант Плюс». - Режим доступа: http://www.consultant.ru/document/cons_ doc_LAW_46892/.

5. Кравченко А.Г., Хажироков В.А. Проблема соотношения законодательных понятий «государственная услуга» и «государственная функция» в правоохранительной деятельности органов государственной власти / А.Г. Кравченко, В.А. Хажироков // журнал Юристъ-Правоведъ. 2016. № 1(74). С. 9-15.

6. Об организации предоставления государственных и муниципальных услуг: Федеральный закон от 27.07 .2010 № 210-Ф3 [Электронный ресурс] // СПС «Консультант Плюс». - Режим доступа: https://www.consultant.ru/ document/cons_doc_LAW_103023/. 


\section{Административное и муниципальное право $10(106) \cdot 2016$}

7. Приказ министерства по делам Севера и поддержке коренных малочисленных народов Красноярского края от 30.06.2014 № 31-о «Об утверждении Административного регламента предоставления министерством по делам Севера и поддержке коренных малочисленных народов Красноярского края государственной услуги по предоставлению материальной помощи лицам из числа коренных малочисленных народов Российской Федерации, проживающим в Туруханском, Енисейском, Северо-Енисейском и Тюхтетском районах Красноярского края, в целях уплаты налога на доходы физических лиц за предоставленные товарно-материальные ценности». [Электронный ресурс] // Официальный интернет-портал правовой информации Красноярского края. Режим доступа: http://www.zakon.krskstate.ru.

8. Распоряжение комитета по управлению государственным имуществом Кемеровской области от 05.04.2012 № 9-2/1180-р «Об утверждении административного регламента комитета по управлению государственным имуществом Кемеровской области по предоставлению государственной услуги «Предоставление государственного имущества Кемеровской области в аренду и безвозмездное пользование». [Электронный ресурс] // Комитет по управлению государственным имуществом Кемеровской области. Режим доступа: http://www.kugi42.ru/ document-22.html.

9. Приказ Минкультуры Республики Хакасия от 25.05.2012 № 84 «Об утверждении Административного регламента Министерства культуры Республики Хакасия по предоставлению государственной услуги «Согласование проведения землеустроительных, земляных, строительных, мелиоративных, хозяйственных и иных работ и проектов проведения указанных работ». [Электронный ресурс] // Архив Республики Хакасия. Режим доступа: http:// khakassia-gov.ru/doc/29396.

10. Приказ Департамента охраны здоровья населения Кемеровской области от 24.05.2010 № 638 «Об утверждении административного регламента предоставления государственной услуги «Направление граждан, нуждающихся в оказании дорогостоящих (высокотехнологичных) видов медицинской помощи, на консультации и лечение в федеральные клиники» [Электронный ресурс] // Архив Кемеровской области. Режим доступа: http://kemer-gov. $\mathrm{ru} / \mathrm{doc} / 24524$

11. Постановление Правительства РФ от 16.05.2011 № 373 «0 разработке и утверждении административных регламентов исполнения государственных функций и административных регламентов предоставления государственных услуг» (с посл. изм. и доп. от 23.01.2014). [Электронный ресурс] // СПС «Гарант». Режим доступа: http:// base.garant.ru/12185976/

12. Об утверждении Административного регламента предоставления Министерством строительства и жилищно-коммунального хозяйства Республики Хакасия государственной услуги по выдаче заключения о соответствии построенного, реконструированного объекта капитального строительства требованиям технических регламентов и проектной документации: Приказ Минрегиона Республики Хакасия от 19.02.2013 № 090-55-п [Электронный ресурс] // Официальный портал Республики Хакасия. Режим доступа: http://r-19.ru/authorities/ ministry-of-construction-housing-and-utilities/docs/administrativnyy-reglament-predostavleniya-ministerstvomregionalnogo-razvitiya-respubliki-khakasiya/9930/

13. Куракин А.В., Юлегина Е.И. Административные регламенты исполнения государственных функций и оказания государственных услуг в области осуществления антикоррупционной экспертизы нормативных правовых актов и их проектов // NB: Административное право и практика администрирования. 2013. № 6. C. 54 - 82 . DOI: 10.7256/2306-9945.2013.6.9040. URL: http://www.e-notabene.ru/al/article_9040.html

\section{References (transliterated):}

1. Vasil'ev V.I. Grazhdanin, zakon i publichnaya vlast': monografiya / I.V. Vasil'ev, A.A. Gravina, E.A. Kurochkina. M.: Norma, 2005. $368 \mathrm{~s}$

2. Rudenko I.A. Ponyatie i sushchnost' gosudarstvennoi uslugi / I.A. Rudenko // Vestnik Saratovskogo gosudarstvennogo sotsial'no-ekonomicheskogo universiteta. 2014. № 3. S. 68-71.

3. Romanyuk L.V. Gosudarstvennaya usluga kak odna iz osnovnykh kategorii gosudarstvennogo upravleniya: ponyatie, sushchnost', soderzhanie / L.V. Romanyuk // Uchenye zapiski Tavricheskogo natsional'nogo universiteta im. V.I. Vernadskogo. 2014. T. 27(66). № 3. - Seriya «Yuridicheskie nauki». S. 119-122.

4. O sisteme i strukture federal'nykh organov ispolnitel'noi vlasti: Ukaz Prezidenta RF ot 9.03.2004 № 314 [Elektronnyi resurs] // SPS «Konsul'tant Plyus». - Rezhim dostupa: http://www.consultant.ru/document/cons_doc_LAW_46892/.

5. Kravchenko A.G., Khazhirokov V.A. Problema sootnosheniya zakonodatel'nykh ponyatii «gosudarstvennaya usluga» $\mathrm{i}$ «gosudarstvennaya funktsiya» v pravookhranitel'noi deyatel'nosti organov gosudarstvennoi vlasti / A.G. Kravchenko, V.A. Khazhirokov // zhurnal Yurist"-Pravoved". 2016. № 1(74). S. 9-15.

6. Ob organizatsii predostavleniya gosudarstvennykh i munitsipal'nykh uslug: Federal'nyi zakon ot 27.07.2010 № 210-FZ [Elektronnyi resurs] // SPS «Konsul'tant Plyus». - Rezhim dostupa: https://www.consultant.ru/document/cons_doc_ LAW_103023/.

7. Prikaz ministerstva po delam Severa i podderzhke korennykh malochislennykh narodov Krasnoyarskogo kraya ot 30.06.2014 № 31-o «Ob utverzhdenii Administrativnogo reglamenta predostavleniya ministerstvom po delam Severa i podderzhke korennykh malochislennykh narodov Krasnoyarskogo kraya gosudarstvennoi uslugi po predostavleniyu material'noi pomoshchi litsam iz chisla korennykh malochislennykh narodov Rossiiskoi Federatsii, prozhivayushchim v Turukhanskom, Eniseiskom, Severo-Eniseiskom i Tyukhtetskom raionakh Krasnoyarskogo kraya, v tselyakh uplaty naloga na dokhody fizicheskikh lits za predostavlennye tovarno-material'nye tsennosti». [Elektronnyi resurs] // Ofitsial'nyi internet-portal pravovoi informatsii Krasnoyarskogo kraya. Rezhim dostupa: http://www.zakon.krskstate.ru. 
8. Rasporyazhenie komiteta po upravleniyu gosudarstvennym imushchestvom Kemerovskoi oblasti ot 05.04.2012 № 9-2/1180-r «Ob utverzhdenii administrativnogo reglamenta komiteta po upravleniyu gosudarstvennym imushchestvom Kemerovskoi oblasti po predostavleniyu gosudarstvennoi uslugi «Predostavlenie gosudarstvennogo imushchestva Kemerovskoi oblasti v arendu i bezvozmezdnoe pol'zovanie». [Elektronnyi resurs] // Komitet po upravleniyu gosudarstvennym imushchestvom Kemerovskoi oblasti. Rezhim dostupa: http://www.kugi42.ru/document-22.html.

9. Prikaz Minkul'tury Respubliki Khakasiya ot 25.05.2012 № 84 «Ob utverzhdenii Administrativnogo reglamenta Ministerstva kul'tury Respubliki Khakasiya po predostavleniyu gosudarstvennoi uslugi «Soglasovanie provedeniya zemleustroitel'nykh, zemlyanykh, stroitel'nykh, meliorativnykh, khozyaistvennykh i inykh rabot i proektov provedeniya ukazannykh rabot». [Elektronnyi resurs] // Arkhiv Respubliki Khakasiya. Rezhim dostupa: http://khakassia-gov.ru/ doc/29396.

10. Prikaz Departamenta okhrany zdorov'ya naseleniya Kemerovskoi oblasti ot 24.05 .2010 № 638 «Ob utverzhdenii administrativnogo reglamenta predostavleniya gosudarstvennoi uslugi «Napravlenie grazhdan, nuzhdayushchikhsya v okazanii dorogostoyashchikh (vysokotekhnologichnykh) vidov meditsinskoi pomoshchi, na konsul'tatsii i lechenie v federal'nye kliniki» [Elektronnyi resurs] // Arkhiv Kemerovskoi oblasti. Rezhim dostupa: http://kemer-gov.ru/ doc/24524

11. Postanovlenie Pravitel'stva RF ot 16.05 .2011 № 373 «O razrabotke i utverzhdenii administrativnykh reglamentov ispolneniya gosudarstvennykh funktsii i administrativnykh reglamentov predostavleniya gosudarstvennykh uslug» (s posl. izm. i dop. ot 23.01.2014). [Elektronnyi resurs] // SPS «Garant». Rezhim dostupa: http://base.garant.ru/12185976/

12. Ob utverzhdenii Administrativnogo reglamenta predostavleniya Ministerstvom stroitel'stva i zhilishchnokommunal'nogo khozyaistva Respubliki Khakasiya gosudarstvennoi uslugi po vydache zaklyucheniya o sootvetstvii postroennogo, rekonstruirovannogo ob"ekta kapital'nogo stroitel'stva trebovaniyam tekhnicheskikh reglamentov i proektnoi dokumentatsii: Prikaz Minregiona Respubliki Khakasiya ot 19.02.2013 № 090-55-p [Elektronnyi resurs] // Ofitsial'nyi portal Respubliki Khakasiya. Rezhim dostupa: http://r-19.ru/authorities/ministry-of-construction-housingand-utilities/docs/administrativnyy-reglament-predostavleniya-ministerstvom-regionalnogo-razvitiya-respublikikhakasiya/9930/

13. Kurakin A.V., Yulegina E.I. Administrativnye reglamenty ispolneniya gosudarstvennykh funktsii i okazaniya gosudarstvennykh uslug $\mathrm{v}$ oblasti osushchestvleniya antikorruptsionnoi ekspertizy normativnykh pravovykh aktov i ikh proektov // NB: Administrativnoe pravo i praktika administrirovaniya. 2013. № 6. C. 54 - 82. DOI: 10.7256/23069945.2013.6.9040. URL: http://www.e-notabene.ru/al/article_9040.html 